\title{
Os pintores de Schopenhauer e Nietzsche
}

\author{
Jair Barboza*
}

\begin{abstract}
Resumo: O artigo mostra como Schopenhauer e Nietzsche recorrem à pintura e à poesia para figurar os principais conceitos de suas filosofias. Aproximam assim filosofia e arte.

Palavras-chave: Schopenhauer - Nietzsche - vontade - pintura - poesia
\end{abstract}

\section{Intróito}

Em minha convivência com as principais obras de Schopenhauer e Nietzsche algo que sempre me chamou, e chama, a atenção é o recurso às artes nos dois autores - especialmente à pintura e à poesia - para "ilustrar" os principais e mais polêmicos conceitos de suas filosofias, vale dizer, os de afirmação e negação da Vontade. $\mathrm{O}$ que proponho aqui é fazer o recorte de algumas dessas passagens no intuito de associar a elas uma iconografia seleta de obras dos pintores mais apreciados por ambos os filósofos, ao lado de Homero (por Nietzsche), o que, penso, permitirá a melhor compreensão do estatuto estético-exegético daqueles conceitos. A iconografia aqui referida, e comentada, foi uma escolha pessoal, excetuando-se a "Santa Cecília" de Rafael, citada explicitamente por Schopenahuer. Escolha essa, porém, que segue justamente a predileção dos artistas indicada pelos próprios filósofos. São obras que demarcam, ao meu ver, o mais fielmente possível o papel dos mestres da pintura no pensamento estético de Schopenhauer e Nietzsche.

* Professor da Universidade Federal de Santa Catarina (UFSC), Florianópolis, Brasil. E-mail: jbarboza@gmx.net. 
Num primeiro momento apresento os principais contornos do pensamento estético destes dois autores. Depois, ao fim de cada apresentação, refiro a iconografia: uma primeira referente à negação, outra à afirmação da vontade. Na conclusão procuro assumir um posição própria sobre o assunto, a partir do que foi apresentado, momento em que dirijo um olhar para a arte contemporânea, ao mesmo tempo em que procuro mostrar como as estéticas de Schopenhauer e Nietzsche não são excludentes, e defendo que elas enriquecem a reflexão contemporânea sobre a experiência estética, para além do estado de desgraça em que caiu o belo na mão das vanguardas. Existe sim uma arte boa e uma arte ruim. Com isto, defendo o cuidado com o espectador mediante a distância a ser considerada entre a realização e a sensibilidade. Ao fim sublinho, com Kant, que a insensatez original é diferente da originalidade.

\section{Os pintores de Schopenhauer}

A célebre frase de Schopenhauer Alles Leben ist Leiden, toda vida é sofrimento, é talvez o melhor ponto de partida para a identificação do lugar e da função da experiência estética em sua filosofia. Isso porque é em contraposição ao estado existencial, marcado pelo sofrimento, que se instaura o estado estético, caracterizado pelo autor como uma hora de recreio em meio aos tormentos da existência. A vida preenche aquele primeiro estado, no qual todos queremos desenfreadamente os mais diversos e multifacetados objetos. Contudo - e aqui começa a lição de anatomia do desejo em Schopenhauer - o querer é uma atividade em si mesma marcada pela carência, já que ele se apresenta em função da falta do seu objeto de satisfação. Esse hiato entre o desejar e a falta do objeto de satisfação conduz ao sofrimento dos seres humanos e animais, que sempre estão à procura de diversas formas de satisfação: alimento, posse, sexo etc. Contudo a metafísica de Schopenhauer postula, em termos imanentes, que a quantidade de matéria do mundo é 
constante e desse modo não há objetos suficientes para as criaturas e os seres em geral. Daí a luta de todos contra todos pela conquista dela, isto é, de objetos para o querer; inclusive uma luta que se dá internamente ao próprio organismo, já que o corpo só se tornou uma singularidade que expõe a espécie orgânica a que pertence porque antes venceu e assimilou representantes de espécies mais baixas, ou seja, as inorgânicas representadas por forças naturais. Dessa perspectiva, o ser humano é um ser para a morte, pois as Ideias inferiores que habitam o seu corpo têm direito preliminar sobre a matéria orgânica e ao fim vão reaver o que em princípio (no tempo) lhes é de direito.

Ora, se a satisfação do querer aparentemente põe fim ao sofrimento, tem-se aí apenas um acontecimento enganoso, já que não demora e outro desejo surge, e, após o novo desejo ser satisfeito, outro bate à porta, e assim por diante, sem trégua: contra cada desejo satisfeito existem pelo menos dez que não o são, e a satisfação é módica, ilusória. Como diz a música: "tristeza não tem fim, felicidade sim". O desejo satisfeito é um "erro conhecido", e o novo desejo a ser satisfeito é um "erro ainda desconhecido". Portanto, afirmar a vontade é, paradoxalmente, afirmar a carência atávica em cada ser: no estado existencial o ser humano assemelha-se em suas fugidias satisfações e alegrias esmigalhadas ao mendigo que hoje recebe uma esmola e tem a vida aliviada por instantes, porém no dia de amanhã vê o seu tormento prolongado.

pelo tempo em que o querer preenche a nossa consciência, pelo tempo em que estamos entregues ao ímpeto dos desejos com suas contínuas esperanças e temores, por conseguinte, pelo tempo em que somos sujeito do querer, jamais obtemos felicidade duradoura ou paz. E em essência é indiferente se perseguimos ou somos perseguidos, se tememos a desgraça ou almejamos o gozo: o cuidado pela Vontade sempre exigente, não importa em que figura, preenche e move continuamente a consciência. Sem tranquilidade, entretanto, nenhum bem-estar verdadeiro é possível. O sujeito do querer, consequentemente, está 
sempre atado à roda de Íxion que não cessa de girar, está sempre enchendo os tonéis das Danaides, é o eternamente sedento Tântalo ${ }^{1}$.

É diante desse cenário tenebroso, desse teatro trágico da chamada representação submetida ao princípio de razão, véu de Maya através do qual só vemos fenômenos, logo, é no mundo temporal e ilusório que renovadamente apresenta motivos moventes ao querer traduzidos em ações distribuídas no espaço, enfim, é no mundo de afirmação da Vontade e do seu foco privilegiado nos humanos e animais superiores, os órgãos genitais, que pode a qualquer instante surgir o sabbath, o sábado reservado ao descanso dos trabalhos forçados. Pode o indivíduo por instantes, numa hora de recreio, tranquilizar-se, pacificar-se ao negar o querer e, desse modo, "perder-se" na contemplação estética, vale dizer, o indivíduo pode absorver-se na intuição de uma Ideia, de um arquétipo eterno, pode absorver-se na chamada "representação independente do princípio derazão" (paraalém dofenômeno)ealcançaratranquilidade de ânimo sem a qual o bem-estar verdadeiro não é possível. Tem-se assim - se reproduzida tecnicamente tal representação - o objeto da arte. Adquire-se uma visão que atravessa o véu de Maya dos fenômenos e intui-se a natureza íntima do objeto. Numa palavra, é o estado estético, instaurado na fruição desinteressada da natureza ou da arte. Com isso, a estética de Schopenhauer, ao contrário das idealistas de Schelling e Hegel, abre amplo espaço em seu interior não só para o belo artístico mas também para o belo natural. Nessa atitude teórica existe uma aproximação de Kant, a ponto de em $O$ mundo como vontade e como representação a própria Ideia exposta na arte ser uma repetição da Ideia intuída esteticamente na natureza.

então aquela paz, sempre procurada antes pelo caminho do querer,

1 SCHOPENHAUER, A. O mundo como vontade e como representação. Trad. Jair Barboza. São Paulo: Ed. Unesp, 2005, p. 266. 
e sempre fugidia, entra em cena de uma só vez por si mesma e tudo está bem conosco. É o estado destituído de dor que Epicuro louvava como o bom supremo e como o estado dos deuses. Pois, nesse instante, somos alforriados do desgraçado ímpeto volitivo, festejamos o sabbath dos trabalhos forçados do querer, a roda de Íxion cessa de girar ${ }^{2}$.

O indivíduo esquece de si. Puro sujeito do conhecimento e Ideia do objeto preenchem a consciência, confundindo-se. Tem-se uma identidade entre quem conhece e o que é conhecido, e, concomitantemente, uma supressão pelo conhecimento das relações estabelecidas entre o querer, o motivo e o objeto; é, por assim dizer, um grau de negação da Vontade (que se consuma na ascese), e quem assim se perde no objeto contemplado obtém um bálsamo para a doença de existir. Schopenhauer chega ao ponto de dizer que no estado estético é indiferente se a contemplação do pôr do sol ocorre a partir de uma prisão ou de um palácio, se os olhos de quem vê pertencem a um mendigo ou a um rei, pois nesse instante a contemplação é impessoal; quem frui o belo é o claro "olho cósmico". Olhos decerto pertencentes aos momentos de máxima inspiração dos pintores que ele cita nominalmente como modelos de uma visão desinteressada do mundo: Rafael, Correggio e J. v. Ruisdael.

A experiência estética, nesses termos, é um estado de exceção, de catarse, de purgação.

A partir dessa concepção, pode-se dizer que, é feliz, no sentido de menos infeliz (já que a felicidade para o autor é um conceito negativo), quem tem receptividade para o belo, pois tem para si assegurada a possibilidade de uma alegria inocente em meio aos tormentos da vida.

Em última instância, com semelhante discurso, o filósofo interroga secretamente os leitores, desafiando-o a pensar se de fato algum dia aprofundou-se radicalmente na experiência estética. É como se o

2 Ibidem, p. 267. 
filósofo perguntasse até que ponto somos suficientemente receptivos à abismal significação de uma bela obra da natureza ou da arte. $\mathrm{O}$ grau de receptividade de alguém para uma obra de arte ou para um belo objeto natural mostra até que ponto vai o seu grau genialidade. Pode-se até mesmo extrair do que acaba de ser dito uma "educação estética" da humanidade: se é certo que a receptividade profunda e emocionada para o belo não pode ser ensinada, mesmo porque isto seria ensinar um sentimento, também é certo que, acostumar-se a pensar que há um estado estético e que todos dispõem de um grau maior ou menor da faculdade de gênio pode em algum momento fomentar talentos, e assim, pela cultura, ampliar o horizonte da busca da saudável fruição estética. Eis por que, no final das suas preleções sobre a Metafísica do belo, o filósofo escreve:

Um filho das musas, do qual deve provir o sal da terra, tem de em seu prazer pertencer às musas e procurar apenas divertimentos espirituais nobres. Jogar, beber e coisas semelhantes são atividades que devem ser deixadas aos filisteus. Que se gaste tempo e dinheiro, antes, indo a óperas e concertos. É sem dúvida incomparavelmente mais nobre e proveitoso quando quatro pessoas se sentam para a audição de um quarteto do que quando se sentam para uma partida de baralho ${ }^{3}$.

Nota-se colateralmente pela citação acima que o contra-ponto crítico da estética aqui em foco deve ser encontrado no conceito de "filisteu", que é uma denúncia direta da banalização do gosto pequeno-burguês. Em seus Aforismos para a sabedoria de vida, o autor define o filisteu como "um ser humano sem necessidades espirituais, em virtude da medida escassa e estritamente normal de suas forças intelectuais"; ele é o "oposto do filho das musas" e permanece alguém "que não aprecia as artes", insensível, ordinário,

3 SCHOPENHAUER, A. Metafísica do belo. Trad. Jair Barboza. São Paulo: Ed. Unesp, 2000, p. 241.

194 | cadernos Nietzsche 31, 2012 
um bárbaro que, em meio à nossa civilização tão carregada e tensa pela luta de todos contra todos, não consegue alimentar deleite por aquilo que a própria civilização tem de nobre. Resulta disso é que o filisteu, ao contrário da pessoa de espírito, não sabe o que fazer com o seu ócio. Sai, por isso mesmo, à cata de prazeres sensuais de todo tipo para preencher o seu vazio interior, pois é pobre em ímpeto para o conhecimento. Mas, embora as ostras, as bebidas, a cerveja e as viagens turísticas o atirem para a satisfação imediata, isto, diz Schopenhauer, não lhe garante a fuga do tédio. Por isso lhe é característico uma seriedade mais grave e seca que se aproxima da seriedade anima (Cf. Schopenhauer 2002, p. 45-6).

Apreciar o belo, infira-se, é também um tipo de secreta resistência à barbárie e ao interesse doentio conectados aos objetos de consumo. O filisteu, diferente do gênio, não sabe o que significa o desinteresse estético, logo, não sabe o que é a paz de espírito dos, por assim dizer, grandes mestres da negação da Vontade.

Passemos, agora, à ilustração (e reflexão estética que ela proporciona) dessa negação da Vontade.

Schopenhauer via em seus pintores prediletos, os "maravilhosos neerlandeses", a intuição puramente objetiva de espírito direcionada "aos objetos mais insignificantes". Pintores que erigiram monumentos duradouros de "paz de espírito". Em especial é J. v. Ruisdael o pintor invocado nessa estética do quietivo. Vemos exposta, diz o autor, nas obras deste grande mestre "o calmo e sereno estado de espírito do artista livre de Vontade". Ele e muitos outros neerlandeses "freqüentes vezes pintaram temas paisagísticos extremamente insignificantes", mas ainda assim produziram todo um efeito consolador de paz de espírito. Temos aí um tipo especial de "alegria estética" (sic!) vinculada ao "puro conhecer e seus caminhos"4.

4. SCHOPENHAUER, A. O mundo como vontade e como representação. Trad. citada, pp. 265-72. 
No horizonte dos maravilhosos neerlandeses podemos citar um pintor recentemente revalorizado, que, em quadros de interior, pendant das paisagens, transforma cenas cotidianas e intimistas num acontecimento universal: Vermeer. Em seus rostos, sejam as pessoas comuns, eruditas ou comerciantes adquirem uma objetividade expressiva em sua mundaneidade que em nada deve aos rostos sagrados de Rafael. Todavia, para me servir do artista citado por Schopenhauer, remeto os leitores às paisagens de J.v. Ruisdael. Nestas saltam aos olhos ora um regato, ora um cemitério, ora um solitário pastor com ovelhas, ora uma montanha: todos envoltos por uma plácida vegetação que parece nos fitar e querer falar conosco. Quietude silenciosa da paisagem. Calma da atmosfera; serenidade do momento. Tranquilidade de ânimo da contemplação (cf. o sítio http://www.wga.hu/indexl.html, verbete "Ruisdael, Jacob Isaackszon van").

Mas é em Rafael e Correggio - nos quais a estética de $O$ mundo... identifica o espírito ético do cristianismo, a resignação e a redenção pelo conhecimento, e o aparenta ao espírito da sabedoria indiana dos vedas - que se encontra "manifesto à intuição", em realizações pictóricas perfeitas, a negação do querer. Deve-se ter em mente que na estética de Schopenhauer a Ideia de humanidade é a mais elevada de todas, de modo que a arte que expõe os lados dessa Ideia é também a arte mais elevada. São os casos das esculturas, poesias e pinturas que tratam do rosto, do corpo, das ações humanos. Mas, sobretudo a pintura, ao valorizar o retrato, mostra o indivíduo como "acentuação" da Ideia de humanidade.

Em seus rostos, especialmente nos olhos, vemos a expressão, o reflexo do modo mais perfeito de conhecimento, a saber, aquele que não é direcionado às coisas isoladas mas às Ideias, portanto que apreendeu perfeitamente a essência inteira do mundo e da vida, conhecimento que, atuando retroativamente sobre a Vontade e ao contrário do outro orientado para as coisas isoladas, não fornece MOTIVOS a ela, mas se torna um QUIETIVO de todo querer, do qual resultou a resignação 
perfeita, que é o espírito mais íntimo tanto do cristianismo quanto da sabedoria indiana, a renúncia a todo querer, a viragem, a supressão da Vontade e, com esta, da essência inteira do mundo, portanto a redenção. Assim, aqueles mestres imortais da arte expressaram intuitivamente em suas obras a sabedoria suprema. Ali se encontra o ápice de toda arte... ${ }^{5}$.

Como ilustração os leitores podem consultar as madonas de Rafael, entretanto refiro aqui a Madonna della Segiola, e as de Correggio, contudo refiro aqui a Virgem com menino Jesus e anjo. Observa-se em tais obras, de um lado, a ternura com que a Madonna de Rafael envolve Jesus e nos mira, como se nos convidasse a partilhar da sua alegria; sentimento que é o mesmo expresso pela Madonna de Correggio ao segurar o seio esquerdo prestes a oferecêlo ao assim chamado redentor. Em ambos os quadros a atmosfera é de calma espiritual (cf. sítio citado, verbetes "Corregio" e "Raffaello Sanzio"). Um quadro de Rafael citado pelo próprio Schopenhauer, na seção $§ 52$ de $O$ mundo..., é "Santa Cecília", justamente no contexto da transição para negação da Vontade de vida na ascese. Como afirma o filósofo, o lado do mundo conhecido de maneira "pura" e a repetição dele em alguma forma de arte é o elemento do artista. $\mathrm{O}$ artista se detém nesse conhecimento profundo do teatro de objetivação da Vontade, isto é, na natureza diante de nós, com as suas diferentes espécies e os seus diferentes indivíduos, num conhecimento da essência das coisas que é "um fim em si". Tratase de um "consolo ocasional" em meio aos tormentos da vida; antes que a força humana finalmente cansada do jogo volte-se para o sério. Como símbolo dessa transição é citada a Santa Cecília de Rafael. O interessante nesta obra, ao meu ver, é, primeiro, a constatação do filósofo de que nela se trata de algo "sério". Por quê? Porque no quadro de Rafael há uma cena que exibe a gravidade de um mundo que, apesar de subsistir, não faz mais sentido em sua existência

5 Ibidem, p.309. 
fenomênica. Noutros termos, Rafael exibe em sua pintura uma espécie de renúncia ao mundo, alegorizada nos instrumentos musicais atirados aos pés da Santa Cecília, pois tais instrumentos, que adquirem sua plena função quando executam peças musicais, perdem-na totalmente, caídos em terra; e o outro instrumento, ainda nas mãos da santa, provavelmente seguirá o mesmo destino. O que importa agora é o coro dos anjos no céu, ouvido por todos os personagens. Essa perda de função dos objetos musicais equivale à perda da significação das coisas do mundo para quem negou a Vontade. Os objetos se tornam nada.

Semelhante interpretação sobre o sentido da obra de Rafael no contexto do pensamento da negação da Vontade de Schopenhauer encontra equivalência e apoio em duas outras imagens citadas na seção § 69 da sua obra magna: a imagem das peças de xadrez que perdem a sua função após o jogo, e a das máscaras de carnaval caídas ao chão após o baile. Passagens que julgo entre as mais belas de um escritor de verve literária que sempre se destacou pelo seu talento na criação de imagens pictóricas e poéticas em vista de ilustrar os seus conceitos filosóficos fundamentais, em especial o de negação da Vontade, que, se de um lado é indizível, de outro, porém, se mostra (cf. a inspiração deste posicionamento para a parte final do Tractatus de Wittgenstein), dando provas assim de um estilo visando a combinar arte e metafísica: artefilosofia.

Ele [o asceta], então, mira calma e sorridentemente a fantasmagoria deste mundo que antes era capaz de excitar e atormentar o seu ânimo, mas agora paira tão indiferente diante de si como as figuras de xadrez após o fim do jogo, ou as máscaras caídas ao chão na manhã seguinte à noite de carnaval, cujas figuras antes tanto nos haviam intrigado $\mathrm{e}$ agitado $^{6}$.

6 Ibidem, p. 495. 
Máscaras de carnaval que intrigavam mas agora encontram-se atiradas à terra sem função alguma, assim como, na "Santa Cecília", instrumentos musicais que antes tocavam, agora encontram-se abandonados à terra sem função alguma. Significativo também para se notar é que o termo Spiel em alemão, usado na presente passagem, traduz-se por "jogo", porém também pode ser vertido, na sua forma verbal spielen, por "tocar" um instrumento; ou ainda por "brincar" (encenar), brincadeira (encenação). Portanto, nas imagens do filósofo relacionadas à música, ao jogo de xadrez e à brincadeira de carnaval, o Spiel parou e o que se tem em seguida é a negação da Vontade de vida é, alegoricamente, a perda de função seja dos instrumentos que tocavam, spielen, ou das peças que jogavam, spielen, ou das máscaras que serviam para brincar, spielen: fim do Spiel.

Os pintores de Nietzsche

O pensamento estético de Nietzsche, para além da sua obra de juventude $O$ nascimento da tragédia no espírito da música, de inspiração marcadamente schopenhaueriana, constrói-se em nítida e confessa oposição ao pensamento do seu mestre. Tendo assumido a sua condição de discípulo de Dioniso, deus da embriaguez e dos excessos orgiásticos, a experiência estética será lida por Nietzsche como o contrário da pacificação do querer. Portanto, em Nietzsche, a experiência estética não é o porto seguro da paz de espírito mas é lida e elogiada como um incentivo ao querer e, desse modo, é uma promessa de felicidade. "O belo é uma promessa de felicidade", diz, citando Stendhal.

O filósofo escreverá num póstumo do inverno de 1883-84 que sua própria posição em face da arte é a de aceitar tão-somente aquela que torna vigorosamente feliz. Uma felicidade que amalgama "prazer e hiper-prazer" e alimenta nossas forças. A arte deve tornar assim visível os desejos, a vontade impetuosa, de uma maneira que 
não impede que a própria crueldade possa ser objeto de fruição. Caso a dor apresente-se como insuportável, é relida na chave das dores da parturiente, ou seja, é a dor necessária à vida, que anuncia danças e sorrisos. A arte, portanto, nada é, se autêntica, senão "afirmação do mundo".

Como se vê, ocorre aqui um resgate daquilo que fora exilado da estética de Schopenhauer: o papel do desejo, da vontade afirmada na experiência estética. Com isso, a arte será boa quando trouxer em si elementos para a excitação. Arte apoteótica, dos grandes volumes, das cores fortes, barroca mesmo. Semelhante arte será pensada como "prova de força". Eis porque, num primeiro momento, Nietzsche se põe fascinado frente à música de Wagner. Por aí também se justifica o seu fascínio por artistas como Homero, Michelangelo e Rubens. Há um momento em que define Homero e Rubens como "artistas da apoteose." E é na rubrica de uma arte da apoteose que esse pensador confere um papel relevante à experiência estética na vida. Toda arte é apreciada e valorada positivamente quando se torna "meio de ajuda e de salvação" da vida "que cresce, que luta".

Assim, se no pensamento de Schopenhauer a boa arte é a da negação do querer; para seu discípulo, que agora segue por caminho próprio, boa arte é aquela que alimenta e afirma a vontade, que doravante se chama vontade de poder. Toda arte, toda filosofia (e Schopenhauer e Nietzsche, como os filósofos românticos de Jena, sempre aproximam arte e filosofia em seus textos), torna-se apreciada e valorada positivamente ao alimentar tensão, em que o sofredor e o agente do sofrimento entram num espaço estético inocentemente transfigurador.

O sofrimento de excesso de vida é, pois, o elemento próprio da arte dionisíaca. Quem o frui tem simultaneamente um olhar trágico para a vida, contra o "empobrecimento" (Verarmung des Lebens) dela, pois sofre de vida na vida e sente este sofrer como uma experiência transfiguradora. A boa arte, por conseguinte, permite que até mesmo o mau, o sem sentido seja igualmente tolerado, ao apontar 
excesso de forças criadoras, temerárias: arte que em qualquer deserto ainda pode semear um campo frutífero, que em qualquer situação de fracasso ou atentado ao viver ainda pode dar origem a uma plasticidade redentora. A bela arte, em suma, é embriaguez, parecida à da excitação sexual. Nietzsche lista na rubrica da embriaguez: a festa, a luta, a vitória, os movimentos extremados, a crueldade, a destruição sob certos influxos meteorológicos ou sob certos narcóticos. Crepúsculo dos ídolos sentencia: "O essencial na embriaguez é a sensação do incremento das forças e o sentimento de excesso. A partir desse sentimento violenta-se as coisas..." (GD/CI, Streifzüge eines Unzeitgemässen 8, KSA 6.116) A experiência estética afirma o foco da vontade, a sexualidade. Nietzsche então invoca Platão, quando este considera que "toda beleza excita à procriação - justamente sendo isso o próprio de seu efeito"; e conclui:

Recordo, contra Schopenhauer e em honra de Platão, que também toda a alta cultura e a literatura da França clássica cresceu sobre o solo do interesse sexual. Deve-se em toda parte procurar o galanteio, os sentidos, o embate sexual, a mulher. (GD/CI, Streifzüge eines Unzeitgemässen 23, KSA 6.126).

Em síntese: "a arte é o grande estimulante da vida".

Quando Nietzsche, nesse cenário, invoca Homero, isto se expõe poeticamente, ao meu ver, no canto XXII da Odisseia, em que se dá o apoteótico trágico por excelência, quando Ulisses, depois de retornar a Ítaca, vinga-se dos pretendentes de Penélope, que na sua ausência queriam esposá-la e não abandonariam o palácio real até que ela se decidisse por um deles. Como todos sabem, ela concebeu um ardil: só se casaria depois de tecer uma colcha, que ela cosia de dia, e desmanchava à noite, atestando assim a sua virtude de esposa. Ora, quando Ulisses retorna ao seu palácio, leva a efeito um vasto massacre. Opera a degola em massa os pretendentes, na qual, obviamente, o vermelho do sangue que jorra dor corpos é a cor predominante, esparramando-se nos montes de corpos que 
tombam ao chão, deles fartamente escorrendo. Os requintes de crueldade desse canto assustam, porém ao mesmo tempo atraem devido à mestria da exposição trágico-apoteótica

Só se ouviam gemidos e gritos;

Crânios partidos rolavam e o sangue o chão todo inundava.

Corre Liodes, os joelhos abraça do herói Odisseu

e, suplicando, lhe diz as seguintes palavras aladas:

"Os teus joelhos abraço, Odisseu, tem piedade e respeito! juro que nunca, em tua casa, ultrajei a qualquer das mulheres, nem com palavras, nem atos; tentei dissuadir, ao contrário, os pretendentes, que tantos abusos aqui praticavam.

Não me quiseram, porém, atender, sem do mal desistirem.

Por esses atos iníquos o triste Destino os alcança.

Só fui arúspice entre eles, sem ser solidário nas obras, e hei de morrer, pois as boas ações já não são retribuídas." Com torvo aspecto lhe disse Odisseu, o guerreiro solerte: "Se eras arúspice entre eles, tal como, orgulhoso, o afirmaste, hás de ter tido, aqui dentro, ocasião de fazer teus pedidos para que a meta do doce retorno me fosse afastada e te seguisse a consorte querida, gerando-te filhos. Não poderás, por tudo isso, escapar do funesto Destino." Disse; e, com mão vigorosa, da espada tomou, que se achava Sobre o chão duro. Tombara da mão de Agelau, quando a Morte o surpreendera. Com ela no meio da nuca o derruba. Ainda a falar, a cabeça rolou para o meio da poeira." $[\ldots]$

Pôs-se, também, Odisseu a espiar pela sala sonora se vivo alguém se encontrava, escapando, assim, da negra Morte. Mas entre grande sangueira e no pó viu a todos caídos, sem exceção, como peixes, que às praias ameiras recurvas os pescadores do mar espumoso tirar têm por hábito em redes feitas de malhas; ali desejosos de às ondas salsas voltar, ficam todos jogados, em montes, na areia, 
té que o sol venha, ardoroso, privá-los a todos da vida: uns sobre os outros jogados, os moços assim se encontravam ${ }^{7}$.

Por esses versos densos, expressivos da dinâmica de uma, aos olhos de Ulissses, justiça praticada, compreende-se melhor o que Nietzsche queria dizer ao referir-se a Homero como o artista da apoteose, ao lado de Michelangelo. Ora, os versos acima selecionados do canto XXII da Odisseia, podemos remeter, pela plasticidade da violência, ao quadro "Rapto das filhas de Leucipo", de Rubens, ou ao "Cristo" raivoso pintado por Michelangelo no teto Capela Sistina, no sentido de que tais pintores têm em comum com o poeta grego, de um lado, a massa densa e compacta de corpos vitimados pelo humor fatídico de raptores - Pólux e Castor em Rubens - de outro a sentença sem apelo de um juiz severo o Cristo de Michelangelo. E, seja na justiça grega ou na justiça cristã interpretada por Michelangelo, não há piedade possível para o infrator de um código pressuposto, e o veredito final conduz ou à degola ou ao padecimento no inferno; nos dois casos a execução da justiça passa por uma mão brônzea. Portanto, a estética de Nietzsche é a dos grandes volumes, dos grandes movimentos, da energia decisiva que não admite o sentimento de compaixão, logo, uma estética da afirmação do querer, que se constituiu por contraste e inversão da estética schopenhaueriana da pacificação do querer.

Nesse horizonte, Rubens aparece como o pintor preferido de Nietzsche. Note-se em obras como "O rapto das filhas de Leucipo", "Hércules bêbado", "Silenus bêbado" e "Caridade romana" os contundentes elementos de uma estética da motivação (cf. sítio acima citado, verbete "Rubens, Pieter Pauwel"). Observamos em Rubens volumosas massas corpóreas e cenas maximamente dinâmicas como aquela do "Rapto" em que Pólux e Castor raptam com mãos brônzeas

7 HOMERO. Odisseia. Trad. Carlos Alberto Nunes. Rio de Janeiro: Ediouro, 2001, canto XXII, pp.374-76. 
as filhas de Leucipo. É uma massa compactada, na qual percebe-se a rotação dos cavalos, dos raptores e das raptadas. A expressão destas é trágica e suplicante, porém dissolvidas na totalidade plástica da cena, interessantemente espionada por um calmo e irônico cupido que nos fita à esquerda do quadro, como que dizendo que tal tragicidade é constitutiva do próprio viver. Essa massa corpórea e dinâmica do grupo de personagens é por vezes representada numa cena de intoxicação alcoólica, como em "Hércules bêbado", no qual o robusto protagonista é sustentado tanto por uma atraente beldade como por feios rostos que despertam aversão. Semelhantes rostos também são vistos na obra "Silenus bêbado", ao pé do qual, logo abaixo, uma mulher embriagada parece esperar o tropeço do pesado Silenus, cuja barriga não desmente a quantidade de álcool ingerida e nos faz assim pensar que a bebida de Dioniso é constantemente sorvida não só por ele e por Hércules mas também por todos aqueles que estão ao redor, festejando desse modo uma atmosfera orgiástica. Os seios de Rubens são eróticos, diferentemente dos seios de Correggio. Que se compare a Virgem amamentando Jesus, no quadro de Correggio anteriormente citado, com os seios do pintor neerlandês na tela "Caridade romana", em que uma mulher alimenta um ancião, que suga faminto o seu seio, antes da execução. E mesmo que o apreciador de pintura volte o seu olhar para as paisagens de Rubens, observará que essa mesma dinâmica corpórea dos quadros se encontra presente, com o que, diferentemente de Ruisdael, a placidez dos objetos insignificantes tornados quietivos é substituída pela robustez e dinâmica, por exemplo, de uma dança em meio ao bosque. Numa paisagem de Rubens, a natureza não é o principal, mas a massa dos corpos humanos.

Michelangelo, como adiantamos, é o outro artista da apoteose escolhido por Nietzsche. Em comum com Rubens o apego às grandes massas, ao dinamismo plástico dos gestos, como, lembrem os leitores, o do teto da Capela Sistina (cf. sítio citado, verbete "Michelangelo Buonarroti"). Apesar de religiosa, a pintura pode ser lida na rubrica da afirmação da vontade, o que dão provas os 
volumes soberbos, os braços e os pés de Cristo a julgar os pecadores, enviando-os ao inferno com a mão esquerda direcionada para baixo, enquanto a direita para o alto indica os redimidos. É um cristo com corpo de atleta, anatomia perfeita, musculoso (ao contrário de certos cristos, especialmente correntes na pintura alemã da mesma época, raquíticos, sofridos, piedosos), que impõe força, desperta medo, não negocia nem se apieda dos que estão em dívida com ele. Essa dramaticidade é, de fato, a de uma vontade de poder que transborda no próprio Cristo, que, distante da tradição pictural cristã, em vez de representado na cruz, aparece julgando no juízo final. Pintores, portanto, que se enquadram perfeitamente na ilustração de uma tensa vontade afirmada. Mesma tensão que se encontra exposta, penso, no antes citado canto XXII da Odisseia de Homero.

\section{Conclusão}

Penso que as posições contrárias de Schopenhauer e Nietzsche aqui expostas não devem ser interpretadas como excludentes, em face, por exemplo, de uma crítica da arte contemporânea, muito menos se deve propor uma acomodação teórica entre elas, mas, ambas indicam-nos que extremos estéticos podem traçar um espaço de fruição e interpretação das artes tanto naquilo que se aproxima do negativo quanto naquilo que se aproxima do positivo, sem que o extremo seja ultrapassado, sem que a experiência estética caia seja na promoção patológica de estados mórbidos de melancolia, ou de excitação. Com isso, uma pergunta interessante soa: o que teria um leitor de Schopenhauer a aprender de Nietzsche e o que teria um leitor de Nietzsche a aprender de Schopenhauer?

Talvez o leitor de Schopenhauer teria a aprender que o excitante e o terror, como representados na poesia de Homero e nos quadros de Rubens, são fruíveis pelo viés da catarse, da purgação, portanto, podem ao fim ser um momento de descarga dionisíaca cujo efeito final é calmante; já um leitor de Nietzsche teria a 
aprender de Schopenhauer que o calmante artístico, o negativo não significa necessariamente turvação, decadência, se tivermos em mente que a pacificação do querer pode proporcionar um tipo de alegria, de sensualidade semelhante à vista nas madonas de Rafael e Correggio, ou seja, o negativo da negação do querer permite a placidez apolínea.

É Aristóteles, por conseguinte, quem soluciona a aparente contradição ou antinomia estética entre Schopenhauer e Nietzsche, e assim nos torna estes pensadores essenciais para a compreensão e crítica da arte em geral, em especial da contemporânea. O terror e a piedade, isto é, tanto aquilo que motiva e excita quanto aquilo que é quietivo e acalma podem ser, na obra de arte bem realizada, objeto de fruição, desde que o artista em sua realização não perca de seu horizonte o cuidado com o espectador, pois sem este não há obra plenamente consumada, pois lhe falta o valor reconhecido, a recepção do impacto a que sempre almeja. Como dizia Kant, na Critica da faculdade de juizo, o artista se ilude ao pensar que desfila melhor num cavalo selvagem do que num domado; ele precisa ter as suas asinhas cortadas, do contrário se torna um insensato original. E, "ter suas asinhas cortadas", no presente contexto, não significa ser domesticado na sensibilidade mas sim produzir uma obra adequada à recepção, indiferentemente de o seu impacto nos remeter ao negativo (negação da vida) ou ao positivo (afirmação da vida).

\footnotetext{
Abstract: The article shows how Schopenhauer and Nietzsche use painting and poetry to ilustrate the most important concepts of their philosophies. In this sense they bind the philosophy with the art.

Keywords: Schopenhauer - Nietzsche - will - painting - poetry
}

\section{referências bibliográficas:}

HOMERO. Odisseia. Trad. Carlos Alberto Nunes. Rio de Janeiro: Ediouro, 2001.

NIETZSCHE, F. Kritische Studienausgabe (Band 6). Hrsg. von Giorgio Colli e Mazzino Montinari. Berlin: de Gruyter, 1999. 
. Historische-kritische Ausgabe. Edição eletrônica baseada na edição de Colli e Montinari. Berlin: de Gruyter, 1994.

SCHOPENHAUER, A. O mundo como vontade e como representação. Trad. Jair Barboza. São Paulo: Unesp, 2005.

. Metafísica do belo. Trad. Jair Barboza. São Paulo: Unesp, 2003.

- Aforismos para a sabedoria de vida. Trad. Jair Barboza. São Paulo: Martins

Fontes, 2002.

Artigo recebido em 05/03/2011.

Artigo aceito para publicação em 15/05/2011. 